\title{
Spectral reflectance indices sense desiccation induced changes in the thalli of Antarctic lichen Dermatocarpon polyphyllizum
}

\author{
Miloš Barták $^{1^{*}}$, Kumud Bandhu Mishra ${ }^{1,2}$, Michaela Marečková ${ }^{1}$ \\ ${ }^{1}$ Laboratory of Photosynthetic Processes, Section of Plant Physiology and Anatomy, \\ Department of Experimental Biology, Faculty of Science, Masaryk University, Univer- \\ sity Campus - Bohunice, Kamenice 5, 62500 Brno, Czech Republic \\ ${ }^{2}$ Global Change Research Institute (CzechGlobe), The Czech Academy of Sciences, v. v. $i$, \\ Bělidla 986/ 4a, 60300 Brno, Czech Republic
}

\begin{abstract}
Lichens, in polar and alpine regions, pass through repetitive dehydration and rehydration events over the years. The harsh environmental conditions affect the plasticity of lichen's functional and structural features for their survival, in a species-specific way, and, thus, their optical and spectral characteristics. For an understanding on how dehydration affects lichens spectral reflectance, we measured visible (VIS) and near infrared (NIR) reflectance spectra of Dermatocarpon polyphyllizum, a foliose lichen species, from James Ross Island (Antarctica), during gradual dehydration from fully wet (relative water content $(\mathrm{RWC})=100 \%)$ to dry state $(\mathrm{RWC}=0 \%)$, under laboratory conditions, and compared several derived reflectance indices (RIs) to RWC. We found a curvilinear relationship between RWC and range of RIs: water index (WI), photochemical reflectance index (PRI), normalized difference vegetation index (NDVI), modified chlorophyll absorption in reflectance indices (MCARI and MCARI1), simple ratio pigment index (SRPI), normalized pigment chlorophyll index (NPCI), and a new NIR shoulder region spectral ratio index (NSRI). The index NDVI was initially increased with maxima around $70 \%$ RWC and it steadily declined with further desiccation, whereas PRI increased with desiccation and steeply falls when RWC was below $10 \%$. The curvilinear relationship, for RIs versus RWC, was best fitted by polynomial regressions of second or third degree, and it was found that RWC showed very high correlation with WI $\left(R^{2}=0.94\right)$ that is followed by MCARI $\left(R^{2}=0.87\right)$, NDVI $\left(R^{2}=0.83\right)$, and MCARI $\left(R^{2}=0.81\right)$. The index NSRI, proposed for accessing structural deterioration, was almost invariable during dehydration with the least value of the coefficient of determination $\left(R^{2}=0.28\right)$. This may mean that lichen, Dermatocarpon polyphyllizum, activates protection mechanisms initially in response to the progression of dehydration; however, severe dehydration causes deactivation of photosynthesis and associated pigments without much affecting its structure.
\end{abstract}

DOI: $10.5817 / \mathrm{CPR} 2018-2-21$

Received December 15, 2018, accepted January 17, 2019.

*Corresponding author: M. Barták<mbartak@sci.muni.cz>

Acknowledgements: The authors would like to express their thanks the CzechPolar2 (LM2015078) infrastructure, J. G. Mendel station at the James Ross Island (Antarctica). The study was also supported by the ECOPOLARIS project (CZ.02.1.01/0.0/0.0/ 16_013/0001708). 
Key words: desiccation, lichens, reflectance and water index, protection mechanisms, survival strategy

Abbreviations: VIS - visible, NIR - near infrared, RWC - relative water content, RI - reflectance index, WI - water index, PRI - photochemical reflectance index, NDVI - normalized difference vegetation index, MCARI - modified chlorophyll absorption in reflectance indices, SPRI - simple ratio pigment index, NPCI - normalized pigment chlorophyll index, NSRI - NIR shoulder region spectral ratio index

\section{Introduction}

Lichens are symbiotic organisms, formed by a natural partnership between fungus and photobionts (e.g., alga or cyanobacteria); they are also regarded as an important contributor during the evolution of life, in this planet, because of their unique survival strategy in extreme harsh conditions of polar or alpine regions. It is assumed that lichens helped, during the initial phase of evolution, in setting a suitable environment via their colonization over the land surface (Heckman et al. 2001). Lichens, in contrast to vascular plants, cannot maintain water - homeostasis, but their water is directly controlled by environmental moisture or external water, and they possess unique ability to deactivate their metabolisms (during extreme dryness or in other harsh situations) and many of their species can stay in the "deactivated state" for several decades; further, they revive their metabolic functions quickly after the resumption of favorable environmental situations. In polar and alpine regions, dynamic environment creates repetitive dehydration stress/re-hydration cycles, and, thus, survival of an organism or lichens, over there, depends on their ability to rapidly de-activate photosynthetic metabolisms. Lichens, in the hydrated and metabolically active state, were indeed found to survive severe biotic/abiotic stresses (e.g., emersion in liquid nitrogen, radioactive contamination, and high irradiance) (reviewed in Mishra et al. 2019). Therefore, it is interesting to investigate the effects of dehy- dration stress on the Antarctic lichen for a better understanding of their survival strategy.

Spectral reflectance provides information on absorption of incident irradiance by foliar pigments after its interactions, and, thus, reflected signals composed of information on alterations in structural, functional, biochemical, and biophysical characteristics of foliar constituents. This method uses several multispectral/hyperspectral sensors, and is commonly being used in remote sensing via air born or satellite-based sensors to find relationship between reflectance spectra (and associated indices) and relevant biophysical/biochemical parameters (e.g., leaf area index (LAI), fraction of photosynthetic active radiation (fPAR), light use efficiency (LUE), and photosynthetic activity). Remote sensing community intends to use reflectance based methods to estimate net or gross primary productivity, to manage forest and/ or agricultural lands, and to monitor effects of environmental changes (Kiang et al. 2007, Malenovský et al. 2009, Granlund et al. 2018); it has been also used for mapping lichen cover (Théau et Duguay 2004). Further, spectral reflectance, together with many other non-invasive methods, are integrated into plant phenotyping research for selection of stress tolerant genotypes (see review Mishra et al. 2016), and also in lichen research (Ager et Milton 1987, Solheim et al.2000, Bechtel etal.2002, Van Der Veen et Csatho 2005, Rees et al. 2004, 
Morison et al. 2014, Barták et al. 2016, Mishra et al. 2019). Reflectance in visible region, $400-800 \mathrm{~nm}$, is highly absorbed by photosynthetic pigments (chlorophylls and carotenoids), and, thus, it also reflects associated photosynthetic activity. There is a red-edge at around $670 \mathrm{~nm}$ because of large absorption (and low reflectance) by chlorophylls, and this is followed by a high reflectance at NIR region $(\sim 750-1200 \mathrm{~nm})$. High reflectance in NIR reflects internal leaf/thallus structure and/or composition of dry matters (e.g., proteins, lignin, and cellulose), and there are two minor water-related wavelengths at $975 \mathrm{~nm}$ and $1200 \mathrm{~nm}$ (reviewed in Liu et al. 2014). Several reflectance indices are derived, from spectral reflectance curves, which may distinguish interspecific differences also in lichens (Bechtel et al. 2002, Rees et al. 2004) as well as their hydration status. For example, Normalized Difference Vegetation Index (NDVI) measures " greenness" (chlorophyll concentration) and structural changes of plant canopies of land surface, Photochemical Reflectance Index (PRI) reflects sudden transition of the leaf from the dark to the light environment due to changes in xanthophyll cycle (Gamon et al. 1992), and Peñuelas et al. (1993) presented a water index (WI) calculated by a simple ratio of reflectance at 970 and $900 \mathrm{~nm}$, among others (for equation see Table 1). Dehydration stress reduces water contents within the thallus of lichens and, thus, it should modulate not only deactivation of active photosynthetic pigments, but also, the structure of thallus during its progression. Therefore, we measured VIS and NIR spectrum with an intention to quest highly sensitive index representing dehydration status of lichens by finding correlations between different reflectance indexes and relative water content (RWC in the Antarctic lichen Dermatocarpon polyphyllizum. Here, reflectance data revealed that dehydration stress initially activates complex protection mechanisms, but severe dehydration stress deactivated activity of photosynthetic pigments without affecting structural features in Antarctic lichen species, D. polyphyllizum.

\section{Material and Methods}

\section{Species characteristics}

Dermatocarpon polyphyllizum (Nyl.) Blomb. and Forssell belongs to the lichen family Verrucariaceae. It usually grows on the rocks in higher altitudes or in Polar regions. The species is reported from the South Shetlands and many sites along the western coast of the Antarctic Peninsula (ANTABIF, Antarctic Biodiversity Information Facility). There are many sites of D. polyphyllizum close to the NE tip of the Antarctic Peninsula, whereas its occur- rence is confined to only a few sites on the eastern coast of the Antarctic Peninsula. D. polyphyllizum, in dry state, has a darkbrown foliose thallus, forming a complex structure of densely stacked and overlapping lobes. Little is known about photobionts of Dermatocarpon sp.; however, green alga Diplosphaera chodatii (Trebouxiophyceae) was identified in a few members of this genus (Fontaine et al. 2012). 


\section{Collection of lichen thalli}

Thalli of D. polyphyllizum were collected from a small-area vegetation oasis, at the northern part of James Ross Island (Ulu Peninsula), which was closely located to the Czech Antarctic station (Mendel), Antarctica. Individual spots of lichen collection were within a Long-Term Research Plot (LTRP, 6348'03' S, $57^{\circ} 52^{\prime} 50^{\prime \prime} \mathrm{W}$ ). This site is nearby the coast and the LTRP is located in between the confluxes of the Bohemian and Algal streams (see Fig. 1). The vegetation oasis is dominated by Bryum pseudotriquetrum that forms carpet of rectangular shape. Longitudinal axis of the carpet follows the line of thawing water pathway from a temporary snowfield that is located $50 \mathrm{~m}$ away from the LTRP. The snowfield represents a major water source to the LTRP during the period of early austral summer. The LTRP is composed of two moss-dominated subareas, and both of them are enriched also with lichens. At wet places with stagnated or slowly flowing water, microbial mats are formed mainly by Nostoc sp. colonies and by algae (prevalently Zygnema sp.). Outside of the moss carpets, a stony surface is covered patchily by several lichen species, e.g., Rhizoplaca melanopthalma, Xanthoria elegans (Halici, Barták, Bačkor - unpublished data).

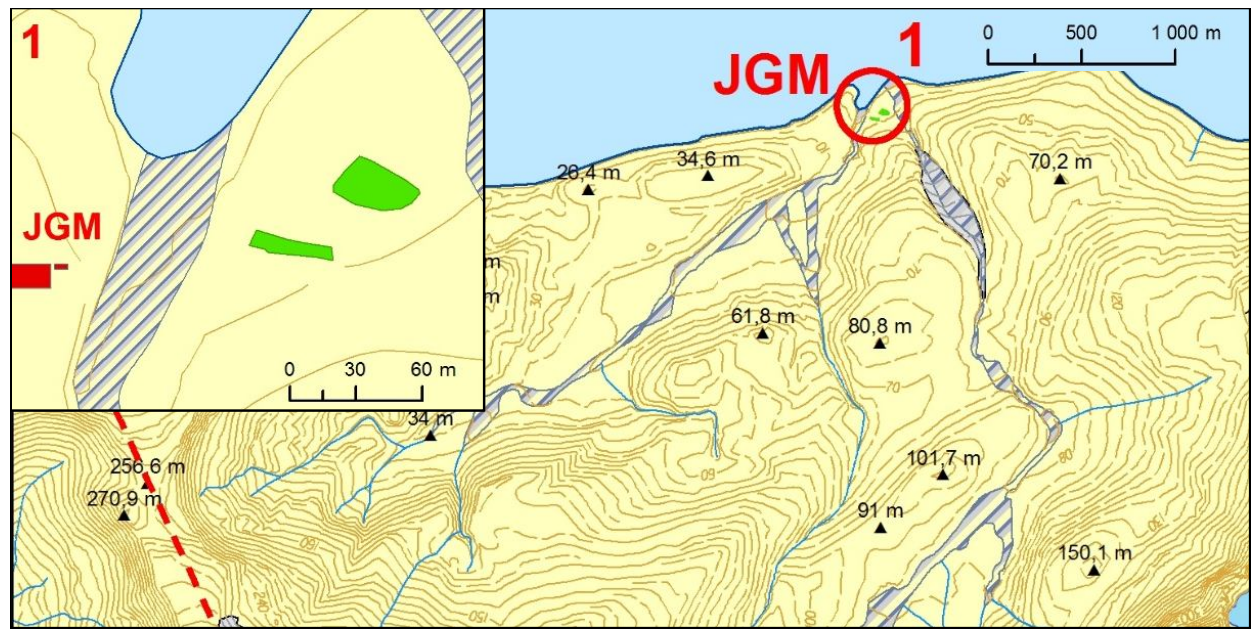

Fig. 1. Location of the long-term research plot (LTRP) in the neighborhood of the Mendel station (Johann Gregor Mendel station (JGM), northern coast of the James Ross Island). Moss carpets are indicated by green color.

\section{Relative Water Content (RWC) during dehydration}

Thalli of $D$. polyphyllizum were fully hydrated at $15^{\circ} \mathrm{C}$ for $24 \mathrm{~h}$ in closed Petridishes until the maximum weight was reached (already tested by weighing on a laboratory analytical scale XA 60/220/X (RADWAG, Poland). Then, the fully-hydrated thalli were allowed to dry at room temperature $\left(18^{\circ} \mathrm{C}, 40 \% \mathrm{RH}\right)$ in a laboratory at the Mendel station (James Ross Island, Antarctica). During desiccation, the thalli were regularly (typically in $\sim 1 \mathrm{~h}$ interval) weighted for evaluating RWC gravimetrically before each measurement of reflectance spectra (see below). Follow- 
ing equation was used to evaluate RWC:

$\operatorname{RWC}(\%)=\left[\left(\mathrm{F}_{\mathrm{w}}-\mathrm{D}_{\mathrm{w}}\right) /\left(\mathrm{W}_{\mathrm{w}}-\mathrm{D}_{\mathrm{w}}\right)\right] * 100$

(Eqn. 1), where $\mathrm{F}_{\mathrm{w}}$ is the actual fresh weight of a sample, $D_{w}$ is the weight of the fully

\section{VIS and NIR spectra measurements}

Reflectance spectra, within the ranges of $380-800 \mathrm{~nm}$ and $627-1060 \mathrm{~nm}$, were measured, respectively, by non-imaging spectroreflectometers, PolyPen RP 400 (UV-VIS) and PolyPen RP 400 (NIR) (Photon Systems Instruments, Brno, Czech Republic). For measuring reflectance spectra, lichen's thalli were placed on a clip of PolyPen's measuring head, which allowed a constant distance between the detector and the lichen. We measured reflectance, in dark, following a short darkening period ( $1 \mathrm{~min}$.$) ; spectral reflectance curves of$ the samples were automatically stored in the device. We calculated several reflectance indices from measured reflected spectra of the lichens: NDVI, PRI, MCARI, MCARI1, SRPI, NPCI (see Table 1).

NIR reflectance spectra were further dry sample (oven-dried sample at $35^{\circ} \mathrm{C}$ for $24 \mathrm{~h}$ ), and $\mathrm{W}_{\mathrm{w}}$ is the weight of the fully hydrated sample. The weighing of thalli and RWC evaluation lasted until a constant weight of dry thalli was reached.

analyzed to evaluate the responses to thallus dehydration on a New Spectral Ratio Index (NSRI) and Water Index (WI); for equation see Table 1. The NSRI is expected to be interesting because originally it was proposed for assessing deterioration of leaf structure due to desiccation. In higher plants, a wavelength-independent increase in spectral reflectance in the NIR shoulder region is typically observed in leaves with slight dehydration. An increase in spectral slope in the NIR shoulder is caused severe leaf dehydration resulting in an alteration in cell structure. We hypothesized that such response would not be found in lichens since they are adapted to repeated dehydration/rehydration cycles and, thus, fast restoration of cell functioning upon rehydration is expected.

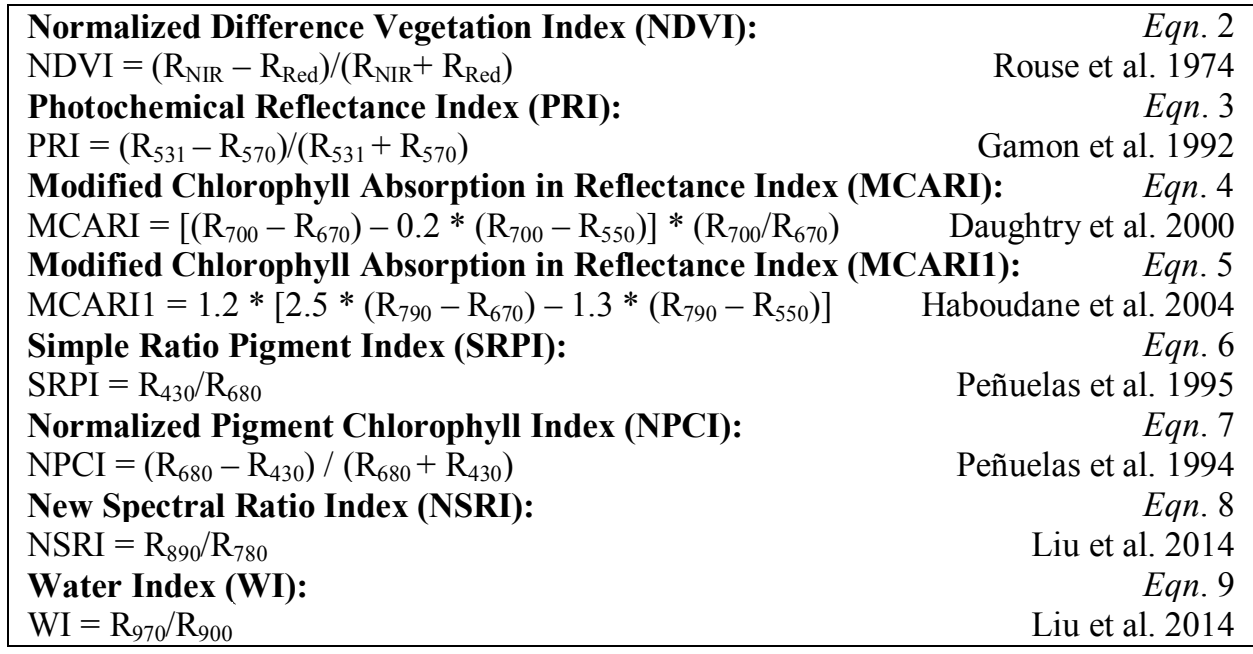

Table 1. Reflectance indices (RIs) calculated from measured VIS and NIR spectral reflectance. 


\section{Results and Discussion}

For the last couple of years, we have been collecting $D$. polyphyllizum and many other symbiotic organisms from field at the James Ross Island, located in Antarctica, with the support of Czech Antarctic Research Programme; we intend to investigate the complex survival strategy of symbiotic organisms in harsh conditions therein (see Marečková et Barták 2016, Mishra et al. 2015, Barták et al. 2016, 2018). Recently, we used the combination of three optical methods, chlorophyll $a$ fluorescence, reflectance, and Raman spectroscopy and investigated hydration induced activation of photosynthesis and synthesis of photosynthetic pigments (chlorophylls and carotenoids) in D. polyphyllizum (Mishra et al. 2019). We found that hydration, in this lichen, activates photosynthesis within $4 \mathrm{~h}$; further, hydration induced structural changes in its thallus, synthesis of chlorophyll molecules and changes in photosynthetic activities were reflected in reflectance signal and its indices NDVI and PRI. The study also reported de novo synthesis of carotenoids, following $24 \mathrm{~h}$ or $48 \mathrm{~h}$ of hydration. Further, we have studied the effects of chilling $\left(\mathrm{T}>0{ }^{\circ} \mathrm{C}\right)$ and freezing $\left(\mathrm{T}<0^{\circ} \mathrm{C}\right)$ temperatures on the fast chlorophyll fluorescence transient (OJIP) and OJIP-derived photosynthetic parameters in $D$. polyphyllizum (Marečková et al. 2019, accepted Feb $3^{\text {rd }}$, in press); we found that fluorescence phase OJIP is highly important to study photobionts of lichens, and the initial phase of the transient, O-J phase, caused by the reduction of the primary quinone acceptor $\left(\mathrm{Q}_{\mathrm{A}}\right)$, was temperature-dependent.

In this experiment, we have used fully hydrated lichen, D. polyphyllizum, and evaluated variations of different RIs versus RWC during its dehydration at laboratory conditions. Typical spectral reflectance curves, recorded for fully wet (RWC $100 \%$ ) and almost fully dried thalli (with RWC $1 \%$ ) of $D$. polyphyllizum, were presented in Fig. 2. The reflectance spectrum of dry thalli was almost linearly increased between 300 to $680 \mathrm{~nm}$; however, rededge in the spectra of fully wet thalli was fully visible along with local peaks at 550 and $640 \mathrm{~nm}$. The peak in $550 \mathrm{~nm}$ is attributed to chlorophyll molecules. The peak has been reported in green chlorolichens (see e.g. Rees et al. 2004). Reflectance spectra with an almost similar shape for dry and wet thalli were reported in Mishra et al. (2019) and Barták et al. (2018).

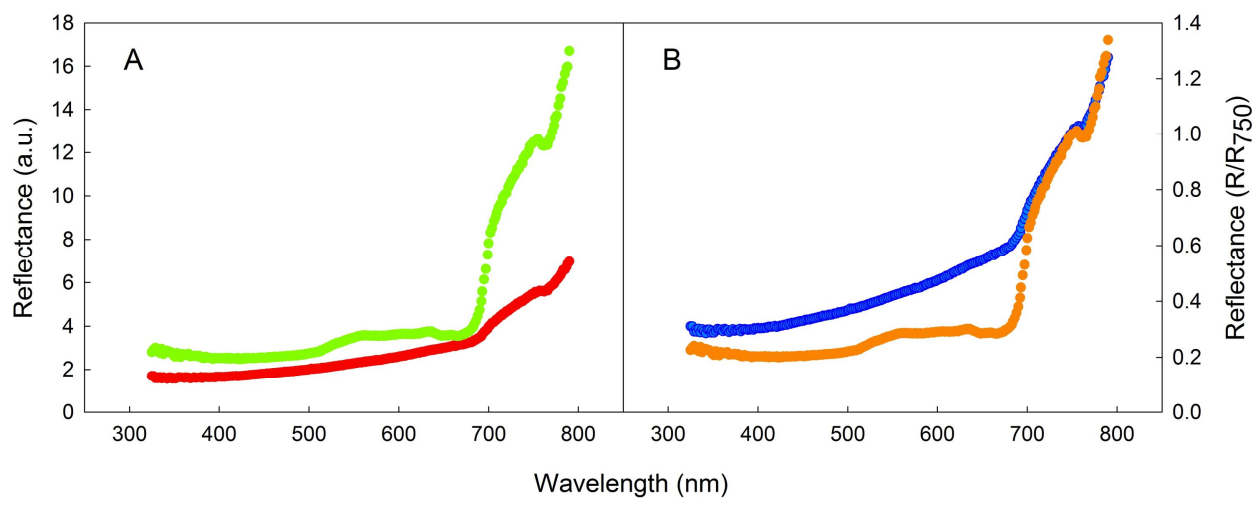

Fig. 2. Raw spectral reflectance curves (A, left panel, measured in range of $300-790 \mathrm{~nm}$ ) of Antarctic lichen Dermatocarpon polyphyllizum and its normalized reflectance curve (B, right panel, normalized to $\mathrm{R}_{750}$ ). Spectral curves were taken in fully wet thalli ( $\mathrm{RWC}=100 \%$, green line, orange line) and dry state ( $\mathrm{RWC}=1 \%$, red line, blue line). 
The plot of different RIs $v s$ RWC showed curvilinear relationships, which were fitted by polynomial equations of second or third orders (Fig. 3), and corresponding coefficient of determination $\left(R^{2}\right)$ for best fits between RWC vs RIs is presented in
Table 2. The best coefficient of determination was found for water index (WI, $\left.R^{2}=0.94\right)$ with 3 order polynomial fits (see Fig. 3). Thus, WI is the most suitable parameter to track the effect of dehydration in D. polyphyllizum.

\begin{tabular}{|c|c|c|c|c|c|c|c|c|}
\hline $\begin{array}{c}\text { Reflectance } \\
\text { indices }\end{array}$ & WI & NDVI & PRI & MCARI & MCRI1 & NPCI & SRPI & NSRI \\
\hline $\begin{array}{c}R^{2} \\
(\mathrm{n})\end{array}$ & $\begin{array}{c}0.94 \\
(3)\end{array}$ & $\begin{array}{c}0.83 \\
(2)\end{array}$ & $\begin{array}{c}0.37 \\
(3)\end{array}$ & $\begin{array}{c}0.87 \\
(3)\end{array}$ & $\begin{array}{c}0.81 \\
(3)\end{array}$ & $\begin{array}{c}0.52 \\
(2)\end{array}$ & $\begin{array}{c}0.54 \\
(2)\end{array}$ & $\begin{array}{c}0.28 \\
(3)\end{array}$ \\
\hline
\end{tabular}

Table 2. Coefficients or determination $\left(R^{2}\right)$ with order (n) of correlation coefficient for best polynomial fits between reflectance indices (RIs) and relative water content (RWC).

Relationship between NDVI and RWC (see Fig. 3) seems biphasic (second order fits) during dehydration; NDVI slightly increases (with a peak at $\sim 70 \%$ of RWC) in the first phase initially when RWC decreased from 100 to $50 \%$; further, decline in RWC (from 50 to $0 \%$ ) caused a pronounced decrease of NDVI from 0.65 to 0.3 with severe dehydration. In general, dehydration response curve of NDVI shows a curvilinear relation with a pronounced decrease in NDVI value at the RWCs below $40 \%$. Such behavior was comparable to the curves recorded earlier for greyishgreen chlorolichens Physconia muscigena and blackish-green cyanolichen Leptogium puberulum (Barták et al. 2018, Orekhova et al. 2018). In lichens, NDVI typically decreases with thallus dehydration, however, the decrease is species-specific (Neta et al. 2010). Recently, Granlund et al. (2018) used normalized difference indices (NDI) from visible to near infrared (VNIR, 400 $1000 \mathrm{~nm}$ ) to evaluate the lichen thallus water content. They concluded that the indices of NDVI are slightly better than the simple ratio index and it has potential, in future, for evaluation of lichen hydration status via remote sensing technologies. Moreover, NDVI has been used for mapping lichen distribution on the Halfmoon Island, South Shetlands, Antarctica (see Casanovas et al.
2015). In our study with $D$. polyphyllizum, PRI, increased with dehydration (when RWC changes from 100 to $20 \%$ ); however, it decreased steeply during dehydration when RWC changes from 10 to $0 \%$ RWC. Barták et al. (2018) reported an almost similar response of PRI vs RWC in P. muscigena (and in L. puberulum). PRI reflects active state of xanthophyll pigments pool, i.e., de-epoxidation state of the carotenoids in particular (see Harris et al. 2014 for review). Therefore, the steep decline in PRI index might be due to deactivation of xanthophyll pigments when RWC falls below $10 \%$ (Fig. 3), and thus, the low value of $R^{2}(0.37)$ for PRI versus RWC is expected. PRI is reported to track photosynthetic activity in higher plants (e.g., Ripullone et al. 2011) and in mosses (Lovelock et Robinson 2002), and it measures photosynthetic light-use efficiency (LUE) as an indicator of stress in higher plants and lichens (Weber et Hill 2016).

Distribution of photosynthetic pigments within photosynthesizing organs and tissues is heterogeneous and their precise quantification has been topic of research for decades. In lichens, NDVI was used to determine the differences between wet and dry thalli (Barták et al. 2016). Similar to NDVI, curvilinear relationship for RWC vs SRPI was obtained with a lower $R^{2}(0.54)$. 


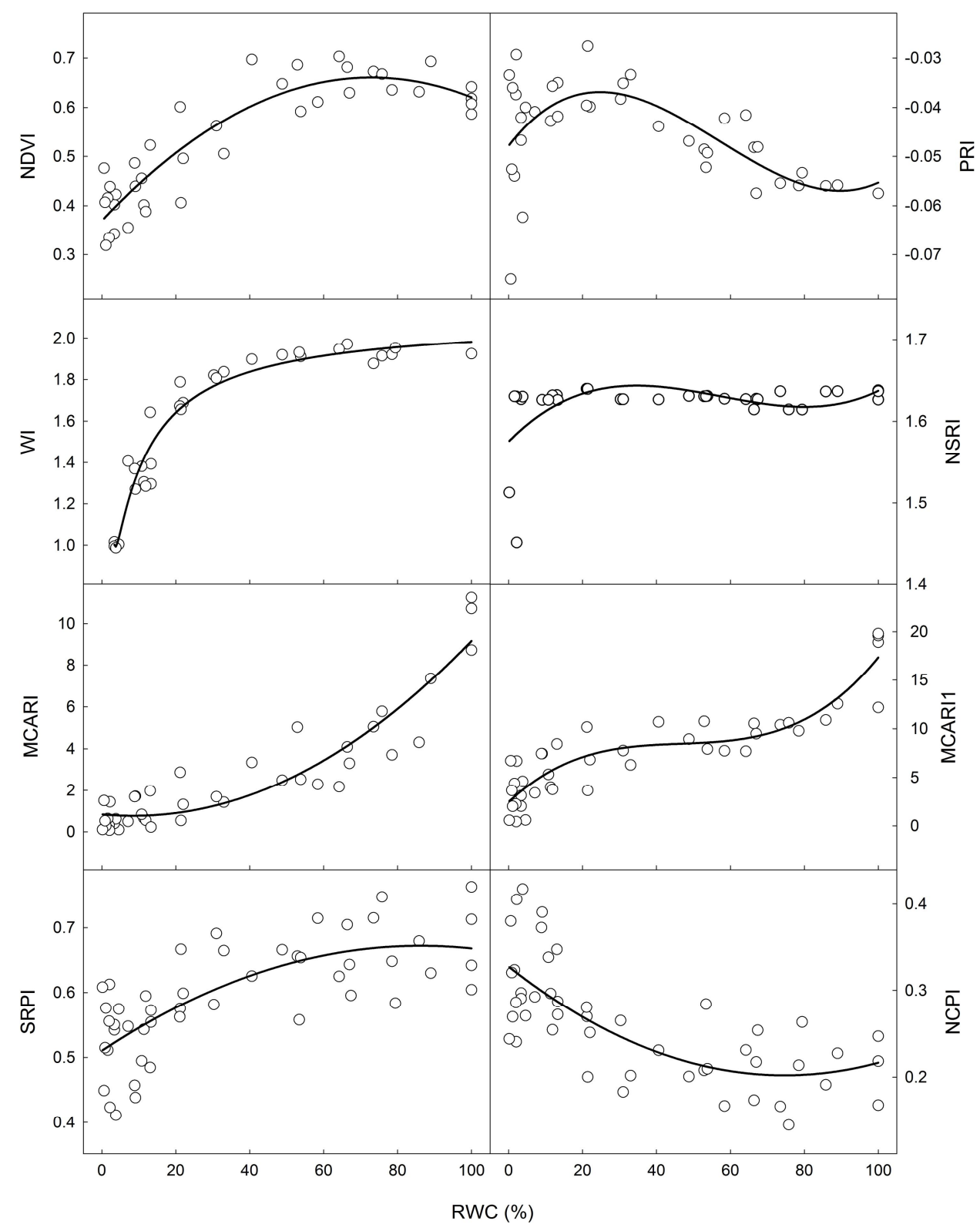

Fig. 3. Plots of polynomial fit between different reflectance indices (RIs) and relative water content (RWC) during induced dehydration of D. polyphyllizum from fully wet (RWC $=100 \%)$ to dry state $(\mathrm{RWC}=0 \%)$. Abbreviations: RWC - relative water content, NDVI - normalized difference vegetation index, PRI - photochemical reflectance index, WI - water index, NSRI NIR shoulder region spectral ratio index, MCARI, MCARI1 - modified chlorophyll absorption in reflectance indices, SPRI - simple ratio pigment index, NPCI - normalized pigment chlorophyll index. 
Other indices, i.e. modified chlorophyll absorption in reflectance indices, MCARI and MCARI1, utilize depth of reflectance at red - edge along with reflectance at 550 $\mathrm{nm}$ and at $700 \mathrm{~nm}$, had $R^{2}$ value 0.87 and 0.81 , respectively. MCARI and MCARI1 were found to be the most sensitive indices (i.e., showing the highest difference between the dry and the wet samples) since they reflect modified chlorophyll absorption in reflectance. Barták et al. (2016) also reported that MCARI was the most effective index to reflect the changes between the dry and the wet state of thallus. We have used the NIR shoulder region index (NSRI), to our best knowledge, for the first time in lichens. NSRI was almost constant
( 1.6) during course of dehydration stress. However, it changed to $\sim 1.4$ when RWC was $0 \%$, and it had the least $R^{2}$ value $\sim 0.28$ (Fig. 3, Table 2).

In contrast to our results, Liu et al. (2014) reported that NSRI increased with the decreasing RWC in herbs and tree species. NSRI was found to be changed with structural deterioration in the leaves (Liu et al. 2014). This may support the idea that lichen $D$. polyphyllizum may deactivate its photosynthetic activity, thanks to dehydration-dependent contraction of cells, by reducing its size when facing severe dehydration; however, there was no damage in its structure within the limit of this experiment (i.e., $\sim 12 \mathrm{~h}$ ).

\section{References}

Ager, C. M., Milton, N. M. (1987): Spectral reflectance of lichens and their effects on the reflectance of rock substrates. Geophysics, 52: 898-906.

Barták, M., Hájek, J., Amarillo, A. C., HazdrovÁ, J. and Carreras, H. (2016): Changes in spectral reflectance of selected Antarctic and South American lichens caused by dehydration and artificially-induced absence of secondary compounds. Czech Polar Reports 6: 221-230.

BArták, M., HáJek, J., MorkusovÁ, J., SkácelovÁ, K. and KošuthovÁ, A. (2018): Dehydrationinduced changes in spectral reflectance indices and chlorophyll fluorescence of Antarctic lichens with different thallus color, and intrathalline photobiont. Acta Physiologiae Plantarum, 40: 177.

Bechtel, R., Rivard, B. and SÁnchez-Azofeifa, A. (2002): Spectral properties of foliose and crustose lichens based on laboratory experiments. Remote Sensing of Environment, 82(2-3): 389-396.

Casanovas, P., Black, M., Fretwell, P. and Convey, P. (2015): Mapping lichen distribution on the Antarctic Peninsula using remote sensing, lichen spectra and photographic documentation by citizen scientists. Polar Research, 34: 25633, doi: 10.3402/ polar.v34.25633.

Daughtry, A. S. T., Walthall, C. L., Kim, M. S., Brown De Colstoun, E. and McMurtrey III, J. E. (2000): Estimating corn leaf chlorophyll concentration from leaf and canopy reflectance. Remote Sensing of Environment, 74: 229-239.

Fontaine, K. M., Beck, A., Stocker-Wörgötter, E. and Piercey-Normore, M. D. (2012): Photobiont relationships and phylogenetic history of Dermatocarpon luridum var. luridum and related Dermatocarpon species. Plants, 1: 39-60.

Gamon, J. A., Peñuelas, J. and Fiels, C. B. (1992): A narrow-waveband spectral index that tracks diurnal changes in photosynthetic efficiency. Remote Sensing of Environment, 41:35-44.

Granlund, L., Keski-SAari, S., Kumpula, T., OKSAnen, E. and Keinanan, M. (2018): Imaging lichen water content with visible to mid-wave infrared $(400-5500 \mathrm{~nm})$ spectroscopy. Remote Sensing of Environment, 216: 301-310.

Haboudane, D., Miller, J. R., Pattey, E., Zarco-Tejada, P. J. and Strachan, I. B. (2004): Hyperspectral vegetation indices and novel algorithms for predicting green LAI of crop canopies: Modeling and validation in the context of precision agriculture. Remote Sensing of Envionment, 90: 337-352. 
Harris, A., Gamon, J. A., Pastorello, G. Z. and Wong, C. Y. S. (2014): Retrieval of the photochemical reflectance index for assessing xanthophyll cycle activity: a comparison of nearsurface optical sensors. Biogeosciences, 11: 6277-6292, doi:10.5194/bg-11-6277-2014.

Heckman, D. S., Geiser, D. M., Eidell, B. R., Stauffer, R. L., Kardos, N. L. and Hedges, S. B. (2001): Molecular evidence for the early colonization of land by fungi and plants. Science, 293: $1129-1133$.

Kiang, N.Y., Siefert, J., Govindjee and Blankenship, R. E. (2007): Spectral signatures of photosynthesis. I. Review of Earth Organisms, Astrobiology, 7: 222-251.

LiU, L., HuAnG, W., Pu, R. and Wang, J. (2014): Detection of Internal leaf structure deterioration using a new spectral ratio index in the near-infrared shoulder region. Journal of Integrative Agriculture, 13: 760-769.

Lovelock, C. E., Robinson, S. A. (2002): Surface reflectance properties of Antarctic moss and their relationship to plant species, pigment composition and photosynthetic function. Plant, Cell and Environment, 25: 1239-1250.

Malenovský, Z., Mishra, K. B., ZemeK, F., Rascher, U. and Nedbal, L. (2009): Scientific and technical challenges in remote sensing of plant canopy reflectance and fluorescence. Journal of Experimental Botany, 60: 2987-3004.

MAREČKOVÁ, M., BARTÁK, M. (2016): Effects of short-term low temperature stress on chlorophyll fluorescence transients in Antarctic lichen species. Czech Polar Reports, 6(1): 54-65.

MAREČKOVÁ, M., BARTÁK, M. and HÁJEK, J. (2019, accepted in press): Temperature effects on photosynthetic performance of Antarctic lichen Dermatocarpon polyphyllizum - chlorophyll fluorescence study. Polar Biology.

Mishra, A., Hájek, J., TuháčKová, T., Barták, M. and Mishra, K. B. (2015) Features of chlorophyll fluorescence transients can be used to investigate low temperature induced effects on photosystem II of algal lichens from polar regions . Czech Polar Reports, 5(1): 99-111.

Mishra, K. B., Mishra, A., Klem, K. and GovindJee (2016): Plant phenotyping: A perspective. Indian Journal of Plant physiology, 21(4): 514-527.

Mishra, K.B., VÍTEK, P. and BARTÁK, M. (2019): A correlative approach, combining chlorophyll a fluorescence, reflectance, and Raman spectroscopy, for monitoring hydration induced changes in Antarctic lichen Dermatocarpon polyphyllizum. Spectrochimica Acta Part A: Molecular and Biomolecular Spectroscopy, 208: 13-23.

Morison, M., Cloutis, E. and Mann, P. (2014): Spectral unmixing of multiple lichen species and underlying substrate. International Journal of Remote Sensing, 35(2): 478-492.

Neta, T., Cheng, Q., Bello, R.L. and Hu, B. (2010): Lichens and mosses moisture content assessment through high-spectral resolution remote sensing technology: A case study of the Hudson Bay Lowlands, Canada. Hydrological Processes, 24: 2617-2628.

Orekhova, A., MarečKová, M., Hazdrová, J. and Barták, M. (2018): The effect of upper cortex absence on spectral reflectance indices in Antarctic lichens during thallus dehydration. Czech Polar Reports, 8: 107-118.

Peñuelas, J., Filella, I., Biel, C., Serrano, L. and Savé, R. (1993): The reflectance at the 950$970 \mathrm{~nm}$ region as an indicator of plant water status. International Journal of Remote Sensing, 14(10): 1887-1905.

Peñuelas, J., Gamon, J. A., Fredeen, A. L., Merino, J. and Field, C. B. (1994): Reflectance indices associated with physiological changes in nitrogen- and water-limited sunflower leaves. Remote Sensing of Environment, 48: 135-146.

Peñuelas, J., Frederic, B. and Filella, I. (1995): Semi-Empirical indices to assess carotenoids/chlorophyll-a ratio from leaf spectral reflectance. Photosynthetica, 31: 221-230.

Rees, W. G., Tutubalina, O. V. and Golubeva, E. I. (2004): Reflectance spectra of subarctic lichens between 400 and $2400 \mathrm{~nm}$. Remote Sensing of Environment, 90: 281-292.

Ripullone, F., Rivelli, A. R., Baraldi, R., Guarini, R., Guerrieri, R., Mangani, F., Peñuelas, J., RADDI, S. and BORGHETTI, M. (2011): Effectiveness of the photochemical reflectance index to track photosynthetic activity over a range of forest tree species and plant water statuses. Functional Plant Biology, 38: 177-186. 
Rouse, J. W., HaAs, R. H., Schell, J. A. and Deering, D. W. (1974): Monitoring vegetation systems in the Great Plains with ERTS, In: S. C. Freden, E. P. Mercanti, M. Becker (eds): Third Earth Resources Technology Satellite-1 Syposium. Volume I: Technical Presentations, NASA SP-351, NASA, Washington, D.C., pp. 309-317.

Solheim, I., Engelsen, O., Hosgood, B., ANDReoli, G. (2000): Measurement and modeling of the spectral and directional reflection properties of lichen and moss canopies. Remote Sensing of Environment, 72: 78-94.

ThÉAu, J., Duguay, C.R. (2004) Lichen mapping in the summer range of the George River caribou herd using Landsat TM imagery, Canadian Journal of Remote Sensing, 30: 867-881.

Van Der Veen, C. J., Csatho, B. M. (2005): Spectral characteristics of Greenland lichens. Géographie physique et Quaternaire, 59: 1-63.

Weber, B., HiLl, J. (2016): Reflectance spectroscopy of biocrusts. In: B. Weber, B. Büdel, J. Belnap (eds.): Biological Soil Crusts: An Organizing Principle in Drylands. Ecological Studies 226, Springer, pp. 216-225. 